\title{
Evaluation of Slovak Automotive Industry Competitiveness Based On Market Concentration Indicators
}

\author{
Vladimír Hojdik ${ }^{1 *}$ \\ ${ }^{1}$ University of Economics in Bratislava, Faculty of Business Management, Department of Business \\ Economy, 85235 Bratislava, Slovakia
}

\begin{abstract}
This paper evaluates the concentration of Slovak automotive industry, and its potential impacts on competitiveness and innovation activities of businesses operating within the industry. It analyses the concentration of automotive industry by using relevant metrics as market share, concentration ratio $\mathrm{CR}_{3}, \mathrm{CR}_{5}, \mathrm{CR}_{10}$ and Herfindahl index. The aim of this paper is to analyze financial results of Slovak automotive businesses, then measure the degree of concentration of whole industry in order to explain industry competitiveness in context of Slovak economy. Finally, the paper should inspire a reader in order to make him consider, what is the impact of strongest automotive companies on whole business environment in Slovak Republic.
\end{abstract}

\section{Introduction}

Automotive industry represents a key sector of the Slovak economy. This industry has some specifics as it includes not only producers, but also suppliers and partially resellers (resellers officially belong to sector of commerce/retail in Slovak environment). For the production of the final product (automobile), wide range of components is necessary and that is why automotive industry is closely connected with the other sectors of the economy. Businesses operating in this sector are cooperating together and create complex supply chains, which fosters the importance of automotive even more.

Sector of automotive has gradually became the most important driver of the Slovak GDP. In the mid-nineties, the first newcoming automotive business was Volkswagen Slovakia in Bratislava. A decade later, Kia Motors Slovakia established their factory in Žilina and PSA Slovakia did the same nearby Trnava, both in 2006. Additional investments helped to build the supply chain what resulted to raising number of businesses producing parts for automakers [14].

By the time, automotive sector became the "backbone" of the Slovak economy. Thus, it is important to assess the competitiveness and concentration ratio within the industry. Both of them, competitiveness and concentration of the automotive sector are closely related to innovation potential of automotive companies what has an enormous effect on the

\footnotetext{
${ }^{1}$ Ing. Vladmír Hojdik, PhD. : vladimir.hojdik@euba. ORCID : 0000-0001-6955-1677.
} 
performance of whole Slovak economy. All in all, this paper aims to build on the results of past studies in order to enrich this research area with new knowledge.

\section{Methods}

The aim of the paper is evaluation of Slovak automotive industry concentration, based on relevant indicators. In the process of the research, we used general and specific research methods. General methods - analysis, comparison, synthesis were predominantly used in introductory part of the paper. Introductory part had mainly theoretical character as it describes current situation and structure of Slovak automotive sector. However, in order to achieve defined aim of the paper, the use of specific methods was the main part of the research.

Specific research methods include:

- mathematical and statistic methods,

- data processing with use of computer editor MS Excel,

- $\quad$ application of special indicators: concentration ratio and Herfindahl index.

Mathematical and statistical methods enabled to quantify the key metrics that allow to assess the competitiveness of industry - in this case automotive industry. First, we had to review market share of businesses (expressed in \%). Based on the market share, we could proceed to quantification of another important indicator - concentration ratio. Concentration ratio depends on market shares of businesses within the industry, and most often is identified for three $\left(C R_{3}\right)$, five $\left(C R_{5}\right)$ and ten $\left(C R_{10}\right)$ businesses with highest market share (also expressed in percent). The final indicator was Herfindahl index (also known as HerfindahlHirschmann index) which measures absolute concentration of industry. Concentration ratio and Herfindahl index are two most frequently used indicators of industry competitiveness measurement [3]. Results obtained from $\mathrm{CR}_{3}, C R_{5}, C R_{10}$ and Herfindahl index quantification became the basis for evaluation of competitiveness within automotive industry.

\section{Results and discussion}

\subsection{Current situation of Slovak automotive industry}

Considering the automotive industry, it is crucial to realize that the sector is not only about automakers. Supply companies have an enormous impact on the sector operation, despite indirectly involved in the car production process. Automotive industry in Slovakia is thus formed by manufacturers (four at the time, mentioned above) together with suppliers and there are close relations between these subjects [14].

According to financial website finstat.sk, the number of businesses operating in Slovak automotive reached up to 350 for year 2018. Among the suppliers with highest revenue we can include Mobis Slovakia, SAS Automotive, Faurecia Automotive or ZF Slovakia which are located on western Slovakia. The strongest suppliers of eastern Slovakia are currently Lear Corporation Seating Slovakia and Marelli Kechnec Slovakia [7].

As listed in the report published by SARIO agency in February 2020, up to 250000 jobs are created directly and indirectly by the automotive industry. Moreover, the share of automotive sector revenues on the total revenues of machinery industry climbed nearly to the level of 50\% in year 2015 [19]. Slovak automotive sector also accounted for more than a third of total exports, reaching totally 35 percent [20]. Table 1 listed below represents a database needed for the research execution, as it completes industry revenues for period 2016 - 2018. All data were obtained from finstat.sk [7].

Table 1. Revenues of top 20 Slovak Automotive Businesses in years 2016-2018 (mil. EUR) 


\begin{tabular}{|c|l|c|c|c|c|}
\hline & & & $\mathbf{2 0 1 8}$ & $\mathbf{2 0 1 7}$ & $\mathbf{2 0 1 6}$ \\
\hline 1. & Volkswagen Slovakia & producer & 10380 & 7549 & 7586 \\
\hline 2. & Kia Motors Slovakia & producer & 5186 & 5185 & 5566 \\
\hline 3. & PCA Slovakia & producer & 2792 & 2694 & 2499 \\
\hline 4. & Mobis Slovakia & supplier & 1480 & 1421 & 1433 \\
\hline 5. & SAS Automotive & supplier & 910 & 644 & 670 \\
\hline 6. & Faurecia Automotive & supplier & 864,3 & 578 & 582 \\
\hline 7. & ZF Slovakia & supplier & 478,1 & 471 & 424 \\
\hline 8. & Yura Corporation & supplier & 381,1 & 363 & 368 \\
\hline 9. & Adient Slovakia & supplier & 346,6 & 454 & 183 \\
\hline 10. & Lear Corporation Seating & supplier & 333,4 & 270 & 184 \\
\hline 11. & Continental Automotive Systems & supplier & 326,8 & 314 & 255 \\
\hline 12. & Marelli Kechnec Slovakia & supplier & 297,9 & 354 & 398 \\
\hline 13. & Faurecia Slovakia & supplier & 285,0 & $\mathrm{X}$ & $\mathrm{X}$ \\
\hline 14 & HBPO Slovakia & supplier & 244,4 & 196 & 191 \\
\hline 15. & Plastic Omnium & supplier & 232,8 & 228 & 182 \\
\hline 16. & Sungwoo Hitech Slovakia & supplier & 212,1 & 206 & 244 \\
\hline 17 & Hyundai Transys Slovakia & supplier & 197,2 & 188 & 205 \\
\hline 18. & Matador Automotive Vráble & supplier & 193,8 & 165 & 149 \\
\hline 19. & Golde Lozorno & supplier & 190,4 & 200 & 248 \\
\hline 20. & Jaguar Land Rover Slovakia & producer & 186,8 & 70 & 28 \\
\hline
\end{tabular}

\subsection{Characteristics of key indicators}

Market concentration and its changes inform about the quality of competition in the economy. Concentration ratio values give institutions an opportunity to monitor the competitiveness of businesses operating in specific sector of economy [16].

The literature is home to numerous methods that evaluate the degree of industry concentration. For purposes of this paper, indicators of absolute concentration were calculated (absolute concentration indicators quantify the degree of concentration in all subjects). Among absolute concentration indicators we include concentration ratio and Herfindahl index [9]. Both indicators are based on the calculation of market share. The fundamental data for indicators quantification are the revenues of individual businesses.

\subsubsection{Market share}

The basic indicator of concentration ratio is the market share. It is share of the individual enterprise revenues on the revenues of whole sector. Market share measures, how the manufacturer performs in comparison to the other market participants. Analytically, it is possible determine it by the following formula [9]: 
where $n$ - number of companies operating in the sector,

$q_{k}$ - revenues of $k$ company, $k=1, \ldots, n$,

$q$ - total revenues for whole sector,

$r_{k}$ - market share of $k$ company.

Market share can be expressed as relative or as percentage result. It takes values from the interval $<0 ; 1>$ for the first, and $\langle 0 ; 100\rangle$ for the latter. Extreme values indicate either full concentration in the industry - monopoly for $r_{k}=1$, or the absence of market operators in the sector for $r_{k}=0$ [9].

\subsection{Concentration ratio $(C R)$}

Concentration ratio is an indicator of the market share sum held by few of the strongest industry companies. Formula of the concentration ratio is as follows [9]:

$$
C R_{\Psi}=\frac{1}{q} * \sum_{k=1}^{\psi} q_{k}
$$

in which $\psi$ lays in the interval $\langle 1 ; n>$ and $C R \psi$ takes values from range $<0 ; 1>$ when calculated in relative numbers, or $<0,100>$ if we calculate percentage results. In practice, the concentration ratio is commonly quantified for three, five or ten strongest companies in the industry. It is therefore quantification of indicators $C R_{3}, C R_{5}$ and $C R_{10}$. In some other studies, authors prefer indicators $C R_{4}$ and $C R_{8}$ quantified for four and eight strongest subjects [15, $17,18]$.

\subsubsection{Herfindahl index}

Herfindahl index measures the absolute concentration in the industry. In the literature we may also be encountered with the concept of the Herfindahl-Hirschmann index [10]. It is used for sector analysis in many countries and it is well-known and commonly accepted indicator of market competition [5]. In this paper, it explains, how financial power (revenues) of individual subjects impacts the concentration of whole industry. Herfindahl index calculates the square of the market share of each subject in the industry and sums up the resulting numbers [6].

Analytical expression of Herfindahl index is as follows [9]:

$$
H=\sum_{k=1}^{n}\left(\frac{q_{k}}{q}\right)^{2}
$$

and the meaning of the variables remains identical, as in the previously defined formulas.

Herfindahl index $H$ takes values from $<1 / n, 1>$. Extreme low value $H=1 / \mathrm{n}$ means that every company has equal market share in the industry. For extreme upper level, for which $H$ $=1$ there is a pure monopoly on the market - one company produces $100 \%$ of whole industry production [4].

In practical use, the Herfindahl index may not be used as a number of the interval mentioned above. It is because in sectors with a higher number of enterprises we would operate with very low numbers. The value of $H$ therefore tends to be adjusted by the appropriate multiplier, most commonly used multiplier is 10,000 . Depending on what is the value $H$ after conversion, we can classify the degree of concentration of the industry, according to the following criteria defined by the US Federal Trade Commission (FTC) :

- for $H<1500$, the industry is concentrated, 
- for $H$ is in the range of $\langle 1500 ; 2500\rangle$, the industry is moderately concentrated,

- for $H>=2500$, the industry is not concentrated [22]. Values of Herfindahl index also impact how government sets and enforces competition policy [13].

The current form Herfindahl index (as we know it today) was firstly applied in 1950 in dissertation thesis of O. C. Herfindahl. Later, in 1959 he used it in a study about international copper industry [11]. The similar concept (sum of squared market shares), however is known since 1940 when A. O. Hirshmann executed a trade study. Hirschmann in his paper suggests that original idea of index belongs to him [12]. Therefore, in the literature we can find concepts of Herfindahl index or Hirchmann-Herfindahl index, but both of them represent the same indicator.

Herfindahl index has been widely used in multiple studies to consider competition level in variety of industries, for example in banking, insurance or automotive sector $[1,5,8,18$, 23]. Its construction, however, has some limitations - it can measure concentration only on geographically isolated markets, but cannot be applied for international companies, as the results may be misleading [2].

\subsection{Quantification of indicators}

In this chapter, we calculate and discuss calculated results. Results are presented in Tables separately for different indicators - market share, concentration ratio and Herfindahl index. Table 2, Table 3 and Table 4 complete all data needed for purposes of the research.

\subsubsection{Market share quantification}

Table 2. Market share of top 10 Slovak automotive businesses in years 2016-2018 (\%)

\begin{tabular}{|c|l|c|c|c|c|}
\hline & & & $\mathbf{2 0 1 8}$ & $\mathbf{2 0 1 7}$ & $\mathbf{2 0 1 6}$ \\
\hline 1. & Volkswagen Slovakia & producer & 34,14 & 28,38 & 29,40 \\
\hline 2. & Kia Motors Slovakia & producer & 17,06 & 19,49 & 21,57 \\
\hline 3. & PCA Slovakia & producer & 9,19 & 10,13 & 9,69 \\
\hline 4. & Mobis Slovakia & supplier & 4,87 & 5,34 & 5,59 \\
\hline 5. & SAS Automotive & supplier & 2,99 & 2,42 & 2,60 \\
\hline 6. & Faurecia Automotive & supplier & 2,84 & 2,17 & 2,26 \\
\hline 7. & ZF Slovakia & supplier & 1,57 & 1,77 & 1,64 \\
\hline 8. & Yura Corporation & supplier & 1,25 & 1,36 & 1,43 \\
\hline 9. & Adient Slovakia & supplier & 1,14 & 1,71 & 0,71 \\
\hline 10. & Lear Corporation Seating & supplier & 1,10 & 1,02 & 0,71 \\
\hline
\end{tabular}

The balance of power between ten strongest businesses based on their market share is reflected in Table 2. Three producers keep the distance while Volkswagen Slovakia, as leading company, clearly holds top position. The revenues progression of producers remains steady during analyzed period, there was no any radical change. Volkswagen Slovakia holds approximately one third of whole industry and controls about half of the market among producers.

In the suppliers subsector, Mobis Slovakia holds its position as the strongest supply company. It also places fourth in the total revenues ranking of the whole industry and nothing has changed on that from 2010 to the present [14]. Even thought Mobis Slovakia has the 
strongest position among suppliers, its revenues are almost ten times lower in comparison to market leader, Volkswagen Slovakia.

Trinity of producers clearly dictate conditions of the Slovak automotive sector. Production among suppliers is significantly fragmented and none of them comes close to the level of producers revenues. The main reason is the character of the products sold - while suppliers sell only parts (B2B model), producers sell the finished product to the customer (B2C model). Producers thus sell products with incomparably higher added value which translate into higher revenues.

\subsubsection{Concentration Ratio quantification}

Concentration ratio of industry is dependant on market share values. As already mentioned before, concentration ratio in the industry is most often calculated for three, five and ten strongest companies in the industry. Table 3 contains already calculated concentration levels $C R_{3}, C R_{5}$ and $C R_{10}$ for the automotive industry in Slovakia, based on revenues achieved by enterprises in the relevant period.

Table 3. Concentration Ratio $C R_{3}, C R_{5}$ and $C R_{10}$ of Slovak Automotive Industry (\%)

\begin{tabular}{|l|l|l|l|}
\hline & $\mathbf{2 0 1 8}$ & $\mathbf{2 0 1 7}$ & $\mathbf{2 0 1 6}$ \\
\hline CR3 & 60,39 & 58,00 & 60,66 \\
\hline CR5 & 68,25 & 65,76 & 68,85 \\
\hline CR10 & 76,16 & 73,79 & 75,60 \\
\hline
\end{tabular}

The results show stable development of concentration ratio during the period. Concentration ratio $C R_{3}$ represents the share of three strongest producers which control about three fifths of the local automotive industry. Their position is dominant and probably anything can threaten it in the near future. Moreover, their hegemony is not short-term at all - they stand on the top of the market since 2010 [14].

Concentration ratio $C R_{5}$ also does not indicate any rapid fluctuations, what applies on $C R_{10}$, too. What is more interesting, however, is comparison of concentration ratios $C R_{5}$ and $C R_{10}$. Analysing $C R_{10}$, we can notice significant asymmetry comparing first 5 strongest and second 5 strongest players. In 2018 the top 5 companies recorded 68,25\% of Slovak automotive production, while the second strongest quintet achieved only $7,91 \%$ of total industry production. Such imbalance is highly inclined to elite five companies and this trend is evident throughout all the years under review. All in all, the data above confirm relatively large differences between financial power of top 10 industry participants.

\subsubsection{Herfindahl index quantification}

A first step before Herfindahl index quantification, a key metric evaluating a degree of industry concentration, was to determine the number of businesses in the sector to 51 ( $\mathrm{n}=$ 51 ), as it would be difficult to include all industry participants (more than 350 ). The first 50 strongest companies are considered as autonomous subjects, other companies in the industry will be merged into the aggregate entity with serial number 51 (other). This simplification will cause slight distortion in Herfindahl index quantification. However, the aggregate market share of other producers reached relatively low values in $4-7 \%$ range. Therefore, the distortion of final result is almost negligible as it does not affect results of Herfindahl index negatively.

Table 4. Herfindahl index of Slovak Automotive Industry in years 2016-2018

\begin{tabular}{|l|l|l|l|}
\hline & $\mathbf{2 0 1 8}$ & $\mathbf{2 0 1 7}$ & $\mathbf{2 0 1 6}$ \\
\hline Herfindahl index H & 1651 & 1400 & 1506 \\
\hline
\end{tabular}


Herfindahl index is a complex indicator of the degree of industry concentration. During the analyzed period, values of Herfindahl index stay in the range of $\langle 1506 ; 1651\rangle$. According to the criteria of the Federal Trade Commission (FTC), the industry can be classified as moderately concentrated (because Herfindahl index is in the interval $<1500 ; 2500>$. This suggestion is underlined by other criterion where Herfindahl index for moderately concentrated industry takes values from interval $<1000 ; 1800>$ [4].

Results of Herfindahl index specify Slovak automotive industry as moderately concentrated industry, however, it is necessary to interpret these results from different perspective. On the one hand, a large number of entities operate in the industry which supports the idea that the sector is relatively open and thus not concentrated. On the other hand, there are three dominant businesses in the sector as they account for two thirds of the total industry revenue, and that favors the thesis of a highly concentrated industry. What is important and positive, that none of the entities possesses the power to use or abuse in their favor. The development of Herfindahl index remains steady between years 2016 - 2018 what points out stable conditions within the industry without significant market fluctuations.

\section{Summary/Conclusion}

Results obtained from the research prove that Slovak automotive industry is highly dependent on performance of three strongest producers. Based on thorough analysis of selected indicators it can be stated that automotive sector in Slovakia has signs of concentrated and also not concentrated industry. According to methodology for Herfindahl index calculation, Slovak automotove industry ranks in the category of moderately concentrated industries what means relatively good competition and suitable conditions for enterpreneurship within the sector.

Succesful development of Slovak economy heavily relies on optimal operating conditions of automotive businesses. Maintenance and improvement of environment within this sector are substancial preconditions for further economic growth. While in 2012 automotive industry contributed to the overall industrial production by $28 \%$, in 2015 this rate reached up to $32 \%$ [20]. The share was continuously rising in following years, reaching the level of $35 \%$ in year 2018 [21]. Table 5 is a summary of facts mentioned above.

Table 5. Share of automotive industry production on whole Slovak industry production in years 2012, 2015 and $2018(\%)$

\begin{tabular}{|l|c|c|c|}
\hline & $\mathbf{2 0 1 8}$ & $\mathbf{2 0 1 5}$ & $\mathbf{2 0 1 2}$ \\
\hline Share & 35 & 32 & 28 \\
\hline
\end{tabular}

Even other financial data confirm the major role of automotive industry. Data obtained from financial website finstat.sk prove, that automotive producers Volkswagen Slovakia, Kia Motors Slovakia and PCA Slovakia placed very high according to net profit or generated value added, when compared to other Slovak companies [7].

Such operation of automotive sector has multiple interpretations. On the one hand, its further expansion should have positive short-term impact on growth of Slovak national economy. From long-term point of view, however, Slovakia should focus on diversification of its economy - national GDP is mostly generated by revenues of automotive sector. Moreover, automotive businesses in Slovakia (especially suppliers) are performing mainly production and operational activities, with lack of investment into innovation or development. The given claims points to fragile and possibly unstable Slovak economy to the future, because of its over-orientation on one sector. Serious financial or investment complications in automotive industry may trigger rising unemployment, decrease of corporate revenues and finally, weakening whole Slovak economy. 


\section{References}

1. F. M. Aijde, J. O. Ajileye, Market concentration and Profitability in Nigerian Banking Industry: Evidence from Error Correctiion Modeling. International Journal of Economics, Commerce and Management 3, 1-12 (2015)

2. P. Aghion, N. Bloom, R. Blundell, Competition and Innovation: An Inverted-U Relationship. Quarterly Journal of Economics 120 (2), 701-728 (2005) DOI : 10.1093/qje/120.2.701

3. J. A. Bikker, K. Haaf, Competition, concentration and their relationship : an empirical analysis of the banking industry. Journal of Banking and Finance 26, 2191-2214 (2002) DOI :10.1016/S0378-4266(02)00205-4

4. I. Brezina, A. Oršulová, J. Pekár, Analýza absolútnej koncentrácie vybraného odvetvia pomocou Herfindahlovho-Hirschmannovhio indexu, Ekonomický časopis 57 (1) 77-94 (2009)

5. I. Brezina, J. Pekár, Z. Čičková, M. Reiff, Herfindahl-Hirschmann index level of concentration values modification and analysis of their change, Central European Journal of Operations Research 24, 49-72 (2016) DOI : 10.1007/s10100-014-0350-y

6. M. C. Cavalleri, A. Eliet, P. McAdam, Concentration, market power and dynamism in the euro area. ECB Working Paper Series, Discussion Paper No. 2253, European Central Bank (2019) DOI :10.2866/379250

7. Database of Slovak Businesses and Organizations - automotive industry. (2016) Available at $\quad<$ https://www.finstat.sk/databaza-firiemorganizacii?activity=Automobilov $\% \mathrm{C} 3 \% \mathrm{BD} \% 20$ priemysel\&sort=sales-desc $>$

8. J. Fedderke, D. Naumann, An Analysis of Industry Concentration in South African Manufacturing 1972-2001, Applied Economics 43, 2919-2939 (2011) DOI : $10.1080 / 00036840802631835$

9. M. Fendek, E. Fendeková, Mikroekonomická analýza (Iura Edition, Bratislava, 2008)

10. G. Grullon, Y. Larkin, R. Michaely, Are US industries becoming more concentrated ? Forthcoming, Review of Finance (2017)

11. O. C. Herfindahl, Copper Costs and Prices : 1870-1957 (Baltimore, The John Hopkins Press, 1964)

12. A. O. Hirschmann, The Paternity of an Index, American Economic Review 54, 761-762 (1964)

13. P. MacKay, G. M. Phillips, How Does Industry Affect Firm Financial Structure ? The Review of Financial Studies 18 (4), (2005) DOI : 10.1093/rfs/hhi032

14. Š. Majtán, V. Hojdík, R. Šlosár, Financial performance of automotive companies and its impact on concentration of automotive industry in Slovak republic, Finance and performance of firms in science, education and practice: proceedings of the 8th international scientific conference : april 26 - 27, 2017, Zlín, Tomas Bata University in Zlín. (2017)

15. E. Nauenberg, K. Basu, H. Chand, Hirshmann-Herfindahl Index Determination under Incomplete Information, Applied Economics Letters 4 (10), 639-642 (1997) DOI : $10.1080 / 758533291$ 
16. S. Rhoades, The Herfindahl-Hirshmann index, Federal Reserve Bank of St. Louis 52 (3), 188-189 (1993)

17. Z. E. L. Rolim, R. R. Oliveira, H. M. Oliveira, Industrial Concentration of the Brazilian Automobile Market and Positioning in the World Market, Working Paper (2019) DOI :10.13140/RG.2.2.11210.11207

18. M. N. Al Arif Rianto, T. B. Awwaliyah, Market share, concentration ratio and profitability : Evidence from Indonesian Islamic Banking Industry. Journal of Central Banking Theory and Practice 2, 189-201 (2019) DOI : 10.2478/jcbtp-2019-0020

19. SARIO, Automotive Sector in Slovakia (Bratislava, SARIO, 2020)

20. Statistical Office of Slovak republic, Yearbook of Industry of the SR 2015 (Bratislava, 2015)

21. Statistical Office of Slovak republic, Yearbook of Industry of the SR 2018 (Bratislava, 2018)

22. U.S. Department of Justice and Federal Trade Commision, Horizontal Merger Guidelines, (2010)

23. D. M. L. Williams, P. Molyneux, J. Thornton, Market Structure and Performance in Spanish Banking. Journal of Banking and Finance 18, 433-443 (1994) DOI :10.1016/0378-4266(94)90002-7

\section{Acknowledgement}

This paper is one of the partial outputs of the research grant no. I-20-103-00 entitled "Assessment of innovation potential in terms of new managerial trends on the base of proposed determinants within automotive industry", led by Ing. Monika Raková. PhD., University of Economics in Bratislava, Faculty of Business Management, Department of Business Economy. 